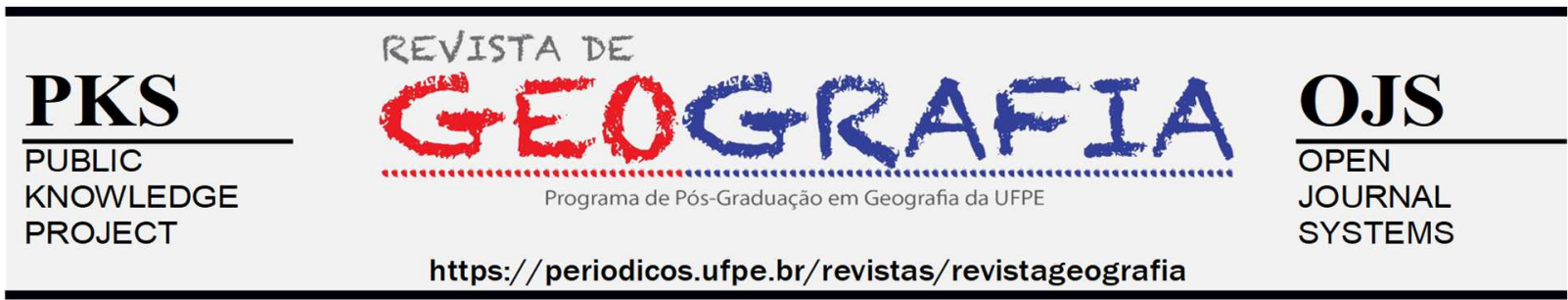

\title{
AVALIAÇÃO DO ÍNDICE DE QUALIDADE DO VAZADOURO A CÉU ABERTO DE BOM SUCESSO-PB
}

\author{
Erick Ferreira de Sousa ${ }^{1}$, Joel Medeiros Bezerra ${ }^{2}$, Jessica Rafaelly Almeida Lopes ${ }^{3}$
}

\begin{abstract}
${ }^{1}$ Bacharel em Engenharia Ambiental e Sanitária pela Universidade Federal Rural do Semi-Árido (UFERSA), Campus Pau dos Ferros/RN, Brasil. E-mail: efdesousa94@gmail.com; https://orcid.org/0000-0002-0116-9671

2 Doutor em Engenharia Agrícola pela Universidade Federal de Campina Grande (UFCG). Professor na Universidade Federal Rural do Semi-Árido (UFERSA), Departamento de Engenharias e Tecnologia (DETEC), Pau dos Ferros/RN. Brasil. E-mail: joel.medeiros@ufersa.edu.br; http://orcid.org/0000-0002-8150-4125

${ }^{3}$ Mestranda em Engenharia Ambiental pela Universidade Federal Rural de Pernambuco (UFRPE). Bacharel em Engenharia Ambiental e Sanitária pela Universidade Federal Rural do Semi-Árido (UFERSA), Campus Pau dos Ferros/RN, Brasil. E-mail: jessicarafaellyalmeida@ hotmail.com; http://orcid.org/0000-0003-0732-8781
\end{abstract}

Artigo recebido em 03/10/2020 e aceito em 02/06/2021

\begin{abstract}
RESUMO
O crescimento populacional acarretou a extração desenfreada dos recursos naturais, causando pressão ambiental e impactos negativos como, por exemplo, a destinação final inadequada dos resíduos sólidos, tornando-se uma das maiores preocupações ambientais, os vazadouros a céu aberto (lixão), pois prejudicam tanto a saúde pública, como a qualidade ambiental. Com isso, o presente trabalho teve como objetivo avaliar a situação ambiental da área do vazadouro a céu aberto do município de Bom Sucesso-PB, mediante aplicação do Índice de Qualidade de Aterros de Resíduos (IQR) e do Índice de Qualidade de Aterros de Resíduos em Valas (IQR-Valas). Para tal, adotou-se neste estudo o método de Índice de Qualidade de Aterros de Resíduos, proposto pela Companhia Ambiental do Estado de São Paulo (CETESB), foi realizada visita in loco a fim de obter informações para o preenchimento dos questionários padronizados de IQR e do IQR-Valas. Paralelo a isso, foi possível verificar as condições socioambiental no entorno do vazadouro, por meio de uma análise espacial. Diante disso, foi possível averiguar que a disposição final dos resíduos sólidos do referido município se encontra em situação inadequada, podendo acarretar poluição e impactos ambientais negativos para água, solo e ar. Além disso, através da análise espacial foi possível observar a proximidade do vazadouro em relação a área urbana, estando distância a $1,5 \mathrm{~km}$ do centro urbano, bem como a presença de corpos hídricos lênticos a pelo menos de 200 a $500 \mathrm{~m}$ do vazadouro. Por fim é notória a necessidade de se utilizar uma tecnologia para a disposição final dos resíduos que apresente os menores impactos possíveis ao ambiente.
\end{abstract}

Palavras-chave: meio ambiente; resíduos sólidos; degradação ambiental. 


\title{
EVALUATION OF THE LEVEL OF QUALITY INDEX FROM THE OPENING SKY BOM SUCESSO-PB
}

\begin{abstract}
Population growth has led to the uncontrolled extraction of natural resources, causing environmental pressure and negative impacts such as, for example, the inadequate final destination of solid waste, becoming one of the greatest environmental concerns, open pit dump (dumps), as they harm both public health and environmental quality. Thus, this study aimed to assess the environmental situation of the open pit dump area in the municipality of Bom Sucesso-PB, by applying the Waste Landfill Quality Index (IQR) and the Waste Landfill Quality Index in Ditches (IQR-Ditches). To this end, in this study we adopted the method of Quality Index of Waste Landfills, proposed by the Environmental Company of the State of São Paulo (CETESB), an on-site visit was carried out in order to obtain information for completing the standardized IQR questionnaires. and IQR-Valas. Parallel to this, it was possible to check the socio-environmental conditions around the dump, through a spatial analysis. In view of this, it was possible to ascertain that the final disposal of the solid residues of the aforementioned municipality is in an inadequate situation, which may cause pollution and negative environmental impacts for water, soil and air. In addition, through spatial analysis it was possible to observe the proximity of the dump in relation to the urban area, being $1.5 \mathrm{~km}$ away from the urban center, as well as the presence of lentic water bodies at least 200 to $500 \mathrm{~m}$ from the dump. Finally, there is a clear need to use technology for the final disposal of waste that has the least possible impact on the environment.
\end{abstract}

Keywords: environment; solid waste; ambiental degradation.

\section{EVALUACIÓN DEL ÍNDICE DE CALIDAD DEL CIELO VACÍO ABIERTO AL BOM SUCESSO-PB}

\section{RESUMEN}

El crecimiento de la población ha llevado a la extracción descontrolada de recursos naturales, provocando presiones ambientales e impactos negativos, como por ejemplo, la disposición final inadecuada de residuos sólidos, vertederos al aire libre (vertederos) una de las mayores preocupaciones ambientales, ya que perjudican la salud pública y salud calidad ambiental. Así, el presente estudio tuvo como objetivo evaluar la situación ambiental del área de botadero a cielo abierto en el municipio de Bom Sucesso-PB, mediante la aplicación del Índice de Calidad del Relleno Sanitario (IQR) y el Índice de Calidad del Relleno Sanitario de Valas (IQR). -Valas). Para ello, en este estudio se adoptó el método de Índice de Calidad de Relleno Sanitario propuesto por la Empresa Ambiental del Estado de São Paulo (CETESB), se realizó una visita in situ para obtener información para completar el Cuestionario estándar IQR. e IQR-Valas. En paralelo, fue posible verificar las condiciones socioambientales que rodean el relleno sanitario, a través de un análisis espacial. Así, se pudo constatar que la disposición final de los residuos sólidos de ese municipio se encuentra en una situación inadecuada, lo que puede generar contaminación e impactos ambientales negativos para el agua, el suelo y el aire. Además, a través del análisis espacial se pudo observar la proximidad del vertedero con relación al área urbana, a 1,5 km del centro urbano, así como la presencia de cuerpos de agua lénticos al menos 200 a $500 \mathrm{~m}$ del vertedero. Por fin, es evidente la necesidad de utilizar una tecnología de eliminación de residuos que tenga el menor impacto posible sobre el medio ambiente.

Palabras-clave: medio ambiente; residuos sólidos; degradación ambiental. 


\section{INTRODUÇÃO}

A geração acelerada dos Resíduos Sólidos Urbanos (RSU) é consequência do crescimento populacional atrelado a expansão econômica e ao processo de urbanização (TANG, 2020). Na maioria dos casos, os RSU apresentam uma composição diversa e têm origem em várias fontes, sendo estes compostos principalmente de material orgânico, recicláveis e rejeitos (SUN et al., 2018). As cidades consomem grandes quantidades de recursos, causando pressão ambiental e impactos negativos (GARCÍA-GUAITA et al., 2018). Fatores como crescimento econômico, aumento da renda, crescimento populacional, rápida urbanização e crescente demanda por bens e serviços contribuem para o aumento da geração de resíduos sólidos (MINGHUA et al., 2009).

De acordo com o panorama divulgado pela Associação Brasileira das Empresas de Limpeza Pública e Resíduos Especiais (ABRELPE), em 2019 a geração de total de RSU alcançou um montante de 79.069.585 t/ano, com uma geração per capita de 1,039 kg/hab./dia. Na região Nordeste a geração de resíduos chegou a 19.700.875 t/ano, dos quais $81,08 \%$, ou 15.973.495 t/ano, foram coletados, e os outros $18,92 \%$, ou $3.727 .380 \mathrm{t} / \mathrm{ano}$, foram destinados para a coleta seletiva. Dos resíduos coletados, 31,5\% foram destinados a vazadouros a céu aberto, 32,9\% a aterros controlados e 35,6\% a aterros sanitários (ABRELPE, 2020).

Os lixões, também chamados de vazadouros a céu aberto, são locais onde o lixo coletado é lançado diretamente sobre o solo, sem nenhuma preparação do mesmo, causando poluição no solo, água (subterrânea e superficial) e na atmosfera (SANTOS; HARAGUCHI, LEITÃO, 2012).

A disposição de lixo diretamente sobre o solo resulta em contaminação, principalmente por metais pesados (PEREIRA, PINTO, PEREIRA, 2013). Quando as águas advindas das chuvas entram em contato com os resíduos ocorre à produção de lixiviado, liquido que causa impactos negativos ao meio ambiente e contamina corpos hídricos superficiais e subterrâneos (BAZIENE e VAZAREVICIUS, 2012). Outro problema é a queima do lixo, produzindo substâncias tóxicas na emissão atmosférica e nas cinzas (WALDMAN, 2013).

Ismael, Leite e Silva (2013) constataram que no aterro comum de Pombal - PB ocorre à queima do material ali disposto e os gases originados dessa queima são tóxicos 
devido à composição química dos resíduos presentes. Este problema repete-se em outros países, Vreeland et al. (2016) apresentaram que a queima dos resíduos sólidos urbanos na Índia é comum, o que resulta em emissões atmosféricas prejudiciais à saúde humana.

Para Mendes et al. (2020) a destinação final inadequada de resíduos sólidos em lixões, gera diversos impactos negativos ao meio ambiente, podendo ocasionar a tríplice poluição (poluição do solo, água e ar), bem como em problemas de saúde pública, contribuindo para a proliferação de doenças causadas por vetores e parasitas.

Segundo Marino et al. (2018) os pequenos municípios são os que enfrentam os desafios mais significativos com a gestão de resíduos sólidos urbanos (RSU) e a implementação de soluções e planos práticos, devido às limitações econômicas, acesso inadequado a tecnologias, dificuldade de organização de planos de resíduos sólidos adequados e treinamento técnico inadequado de profissionais.

Por isso, a gestão de resíduos deve seguir o que preconiza a Política Nacional de Resíduos Sólidos (PNRS) a partir da Lei 12.305/2010 que visa a proibição da destinação inadequada de resíduos. Sendo que o manejo de forma adequada envolve coleta, transporte, tratamento e disposição final, de forma apropriada, do lixo doméstico, e quando esse modelo não é seguido de forma correta acarreta problemas a saúde humana e impactos ambientais aos ecossistemas (BRASIL, 2010).

Neste sentido, muitos trabalhos têm sido desenvolvidos através da metodologia de aplicação do IQR nos mais variados locais do país (SANTOS, HARAGUCHI, LEITÃO, 2012; SILVA et al., 2012; GANDELINI, CAIXETA FILHO, 2007; ALBERTIN et al., 2011) o que permite um diagnóstico da situação do destino final dos nossos resíduos. Lunes et al. (2016) desenvolveram um estudo com a aplicação do IQR e IQR-Valas no município de Pau dos Ferros/RN, analisando a situação da disposição final dos resíduos em uma cidade do interior do Nordeste, mostrando a difusão dessa modelo da CETESB e contribuindo com a construção da ciência no interior do Nordeste.

Diante desse cenário, o estudo buscou avaliar as condições ambientais de destinação final dos resíduos sólidos de Bom Sucesso-PB, a fim de inferir a situação ambiental da área do vazadouro a céu aberto (lixão), mediante aplicação do Índice de Qualidade de Aterros de Resíduos (IQR) e do Índice de Qualidade de Aterros de Resíduos em Valas (IQR-Valas). 


\section{METODOLOGIA}

\section{Área de estudo}

O município de Bom Sucesso situa-se na região Oeste do Sertão Paraibano, na microrregião de Catolé do Rocha (Figura 1). Faz fronteiras ao norte com as cidades de Alexandria-RN e Brejo dos Santos-PB, ao leste com Brejo dos Santos-PB e Jericó-PB, ao sul com Lagoa-PB e a Oeste com Alexandria-RN e Santa Cruz-PB (IBGE, 2017).

Figura 1: Localização do município de Bom Sucesso-PB.

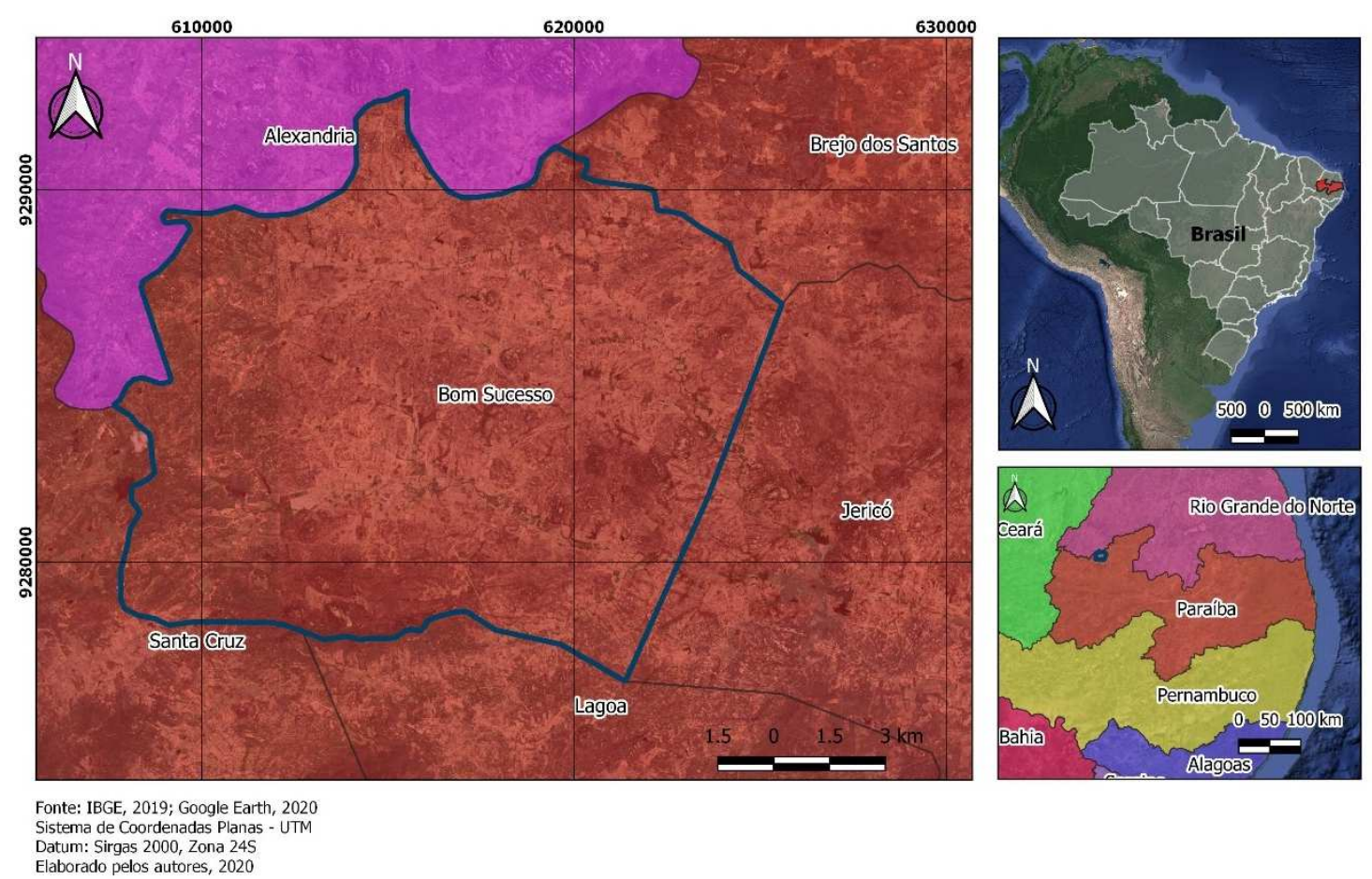

Fonte: Sousa et al., 2020.

O município foi criado pela Lei n⿳⺈ 3.049, de 17 de junho de 1963, e instalado em 02 de agosto de 1963. Bom Sucesso-PB possui uma área de $184,102 \mathrm{~km}^{2}$ e uma população de 4.956 habitantes, de acordo com a estimativa para o ano de 2020, o que equivale a uma densidade demográfica de 26,92 hab./km² (IBGE, 2020). 


\section{IQR e IQR - Valas}

Caracterizado como uma pesquisa qualitativa de campo, com caráter exploratório, utilizou-se a documentação direta, através da observação sistemática (visitas in loco) e indireta. Foram realizadas visitas ao Vazadouro a céu aberto de Bom Sucesso-PB com o intuito de executar um levantamento sistemático da disposição final dos resíduos sólidos urbanos locais e registrar os impactos ambientais existentes.

Foi realizada a identificação do Índice de Qualidade de Aterros de Resíduos (IQR), tal como avaliado o IQR-Valas, ambos propostos pela Companhia Ambiental do Estado de São Paulo - CETESB (2019), caracterizados como metodologias que consideram os impactos ocasionados nos meios físicos, bióticos e antrópicos, avaliando itens referentes a estrutura de apoio, frente de trabalho, bermas e taludes, superfície superior, estrutura de proteção ambiental, características da área e funcionamento do local.

A utilização de um índice abrangente, devidamente fundamentado, que leva em consideração as condições encontradas por ocasião das inspeções, permite efetuar uma estimativa confiável das condições ambientais, diminuindo a subjetividade na análise dos dados.

O IQR e o IQR-Valas são questionários estruturados que consistem na atribuição de pesos aos trinta e três parâmetros ambientais, variando entre 0 e 10, incorporando critérios de pontuação e classificação dos locais de destinação, avaliando as características locacionais, estruturais e operacionais. O questionário é dividido em três subtotais, por onde realiza-se o somatório destes e divide-se por 10. Entretanto em casos que ocorra o recebimento de resíduos industriais o valor deverá ser divido por 11. O valor encontrado será considerado adequado se estiver entre 7,1 a 10,0 e inadequado caso esteja entre 0,0 e 7,0 (CETESB, 2020). O índice leva em consideração a situação atual do local tendo em vista que o dinamismo operacional e as variações climáticas podem provocar mudanças nos resultados (CETESB, 2020).

Uma análise espacial foi realizada para verificação da disposição do vazadouro em relação aos aspectos socioambientais da região. Foram obtidos os vetores da hidrografia, contendo os corpos hídricos superficiais lóticos e lênticos, com suas respectivas Áreas de Preservação Permanente (APP) conforme indicado no Código Florestal Brasileiro, utilizando 
30 metros para as faixas de rios e 50 metros para os lagos e lagoas naturais em área rural (BRASIL, 2012), além da identificação da área urbana consolidada no entorno, configurando os núcleos populacionais.

Procedeu-se uma análise espacial da distância euclidiana do vazadouro no raio de 1000 metros, visando identificar a disposição dos aspectos socioambientais analisados. Todos os procedimentos foram realizados no software QGIS v. 2.18 e espacializados em projeção plana UTM, Datum SIRGAS 2000 no fuso 24S. Além disso, para complementar a análise in loco foram realizados registros fotográficos para enfatizar a análise do IQR e do IQR-Valas, tal como averiguar as características avaliadas. Sendo utilizados ainda programas e equipamentos como: Google Earth Pro, receptor GPS de navegação, com os quais pode-se obter imagens de superfície terrestre, pontos georreferenciados, espacialização do local e possibilitando identificar áreas com potencial de contaminação.

Os dados referentes ao histórico de uso da área foram coletados por meio de formulários e observações. Os quais vislumbraram obter dados referentes ao tempo de funcionamento do vazadouro, o tipo de material depositado e a forma como as atividades na área foram desenvolvidas.

Para caracterizar a atual situação da área do vazadouro de Bom Sucesso e seu entorno foram coletados dados relativos ao solo, água e ar, além de meios bióticos como a fauna e flora da região. Sendo necessário estimar dados sobre o vazadouro, como o total de resíduos dispostos na área, uma vez que este tipo de área degradada não dispõe de controle de entrada e saída de materiais.

\section{RESULTADOS E DISCUSSÃO}

O vazadouro a céu aberto de Bom Sucesso está localizado em seus limites, estando situado nas proximidades da área urbana, numa distância de $1,5 \mathrm{~km}$ do centro da cidade. Além disso, verificou-se a presença de corpos hídricos superficiais próximos a área do vazadouro (Figura 2). 
Figura 2: Localização do vazadouro em relação à área urbana de Bom Sucesso-PB e aos corpos hídricos existentes.

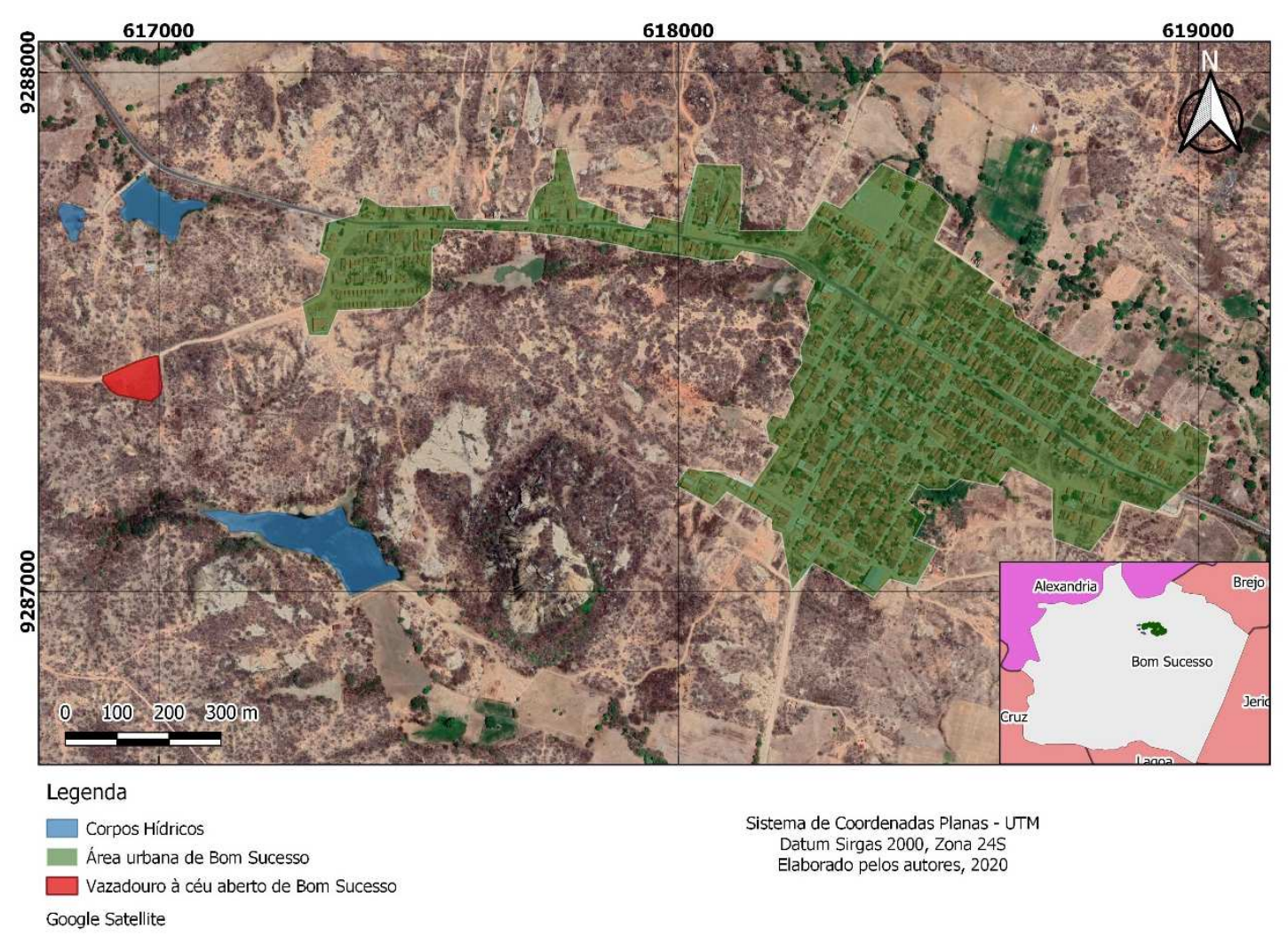

Fonte: Sousa et al., 2020.

Segundo Sousa, Bezerra e Lopes (2020) o vazadouro iniciou sua operação desde 2001, conforme a Lei no 199/2001 que dispõe sobre a compra do terreno para implantação do vazadouro. O terreno adquirido pelo município para funcionamento do vazadouro possui as seguintes dimensões: $136 \mathrm{~m}$ ao norte, $89 \mathrm{~m}$ ao sul, $92,5 \mathrm{~m}$ a leste e $51 \mathrm{~m}$ a oeste.

O vazadouro recebe, de segunda a sexta-feira, os Resíduos Sólidos Urbanos (RSU) da cidade, recolhidos por caminhão compactador, no período da manhã. De acordo com Sousa, Bezerra e Lopes (2020) a produção diária de RSU se aproxima de $1000 \mathrm{~kg}$, chegando à estimativa de geração per capta de $0,499 \mathrm{~kg} / \mathrm{hab} / \mathrm{dia}$. Além dos RSU, outros rejeitos são destinados, como pode ser observado nos registros fotográficos obtidos mediante visita in loco (Figura 3), como: resíduos de abatedouros, construção civil, comércios, agrícolas, varrição publica, lixo eletrônico e lodo provenientes de limpeza de fossa. 
Figura 3: Vazadouro de Bom Sucesso-PB: a) Queima. b) Corpos hídricos próximos. c) Restos de animais. d) Catador.
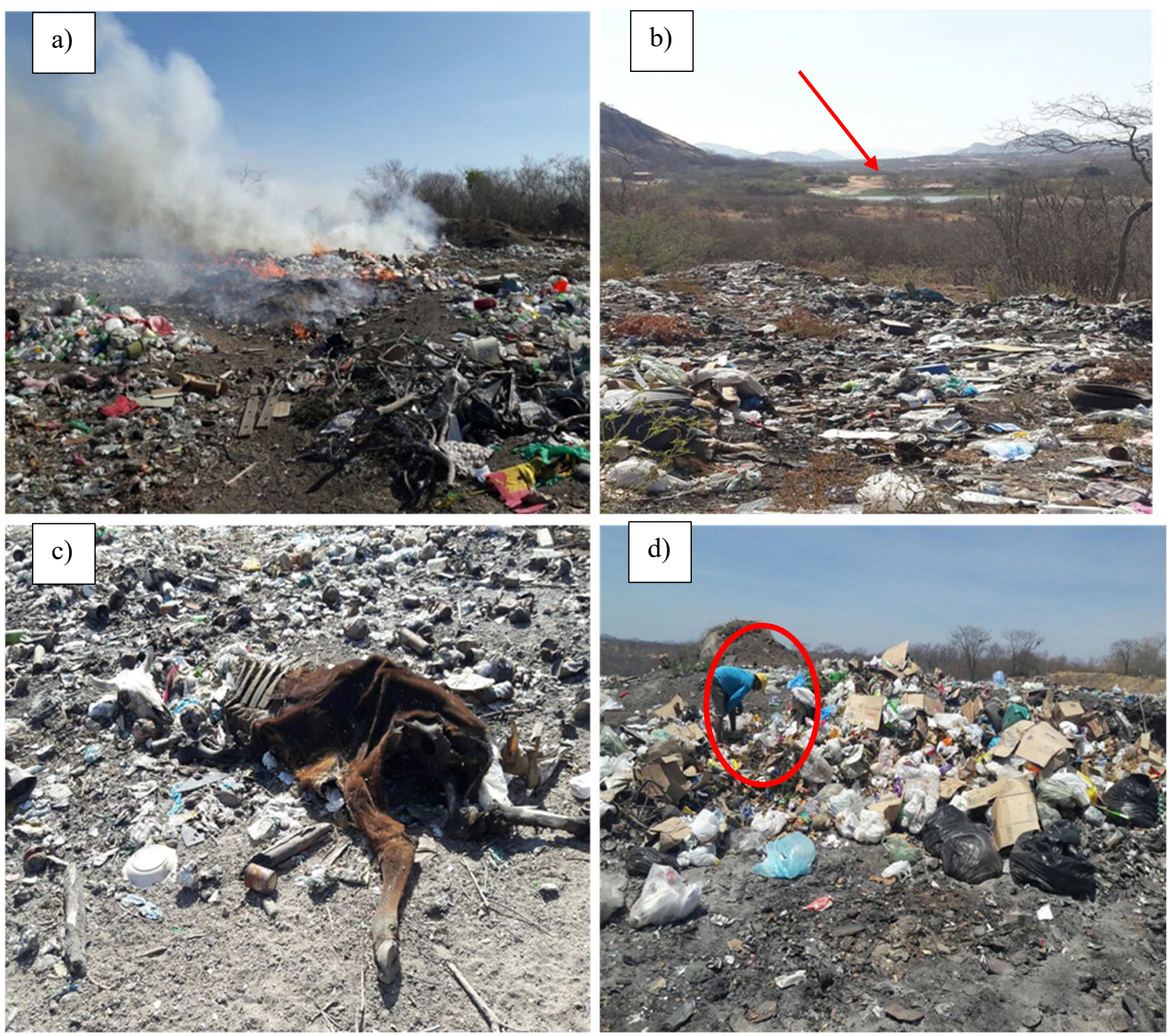

Fonte: Autores, 2020.

É notória a presença de animais, insetos, odor e fumaça advinda da queima desses resíduos, tornado uma condição insalubre. Segundo Holgado-Silva et al. (2014) a queima dos resíduos sólidos é a destinação mais utilizada pelos moradores, principalmente em zona rural. No entanto, também são medidas adotadas na zona urbana, assim como Lopes et al. (2016) e Lunes et al. (2016) constataram no vazadouro de Pau dos Ferros-RN, visando reduzir o volume de resíduos depositados nessas áreas. 
De acordo com Sousa, Bezerra e Lopes (2020) a cidade não possui coleta seletiva, porém existe um catador que faz a segregação entre recicláveis e rejeitos, sendo que todo material reciclado é vendido a atravessadores. Segundo informações fornecidas pelo catador, o mesmo recolhe mensalmente uma média de $1000 \mathrm{~kg}$ de plástico, $5 \mathrm{~kg}$ de cobre, $50 \mathrm{~kg}$ de alumínio e 100 kg de melissa (sandálias de plástico).

Ao avaliar as condições e estruturas do vazadouro constatou-se valores de 1,8 e 4,0 para o IQR e o IQR-Valas, respectivamente. Tais condições do equipamento de disposição final de RSU classificam-se como inadequadas de acordo com a CETESB (2020). O que evidencia a precária situação desta área onde os rejeitos são dispostos a céu aberto, ocorrendo a inexistência de tratamento.

Os Quadro 1 e 2 apresentam a avaliação do IQR e do IQR-Valas, respectivamente, para o vazadouro de Bom Sucesso. No Quadro 1, pode-se observar do Índice de Qualidade de Aterros (IQR).

Quadro 1: Avaliação do Índice de Qualidade de Aterros de Resíduos do vazadouro a céu aberto de Bom Sucesso,

\begin{tabular}{|c|c|c|c|c|}
\hline \multicolumn{5}{|c|}{ Paraíba. } \\
\hline ITEM & SUBITEM & AVALIAÇÃO & PESO & PONTOS \\
\hline \multirow{8}{*}{$\begin{array}{c}\text { Estrutura de } \\
\text { apoio }\end{array}$} & \multirow{2}{*}{ Portaria, balança e vigilância } & Sim/ Suficiente & 2 & \multirow{2}{*}{0} \\
\hline & & Não/Insuficiente & 0 & \\
\hline & \multirow[b]{2}{*}{ Isolamento físico } & Sim/ Suficiente & 2 & \multirow[b]{2}{*}{0} \\
\hline & & Não/Insuficiente & 0 & \\
\hline & \multirow[b]{2}{*}{ Isolamento visual } & Sim/ Suficiente & 2 & \multirow[b]{2}{*}{0} \\
\hline & & Não/Insuficiente & 0 & \\
\hline & \multirow{2}{*}{ Acesso à frente de cargas } & Adequado & 3 & \multirow[b]{2}{*}{0} \\
\hline & & Inadequado & 0 & \\
\hline \multirow{5}{*}{$\begin{array}{c}\text { Frente de } \\
\text { trabalho }\end{array}$} & \multirow[b]{2}{*}{ Dimensões da frente do trabalho } & Adequado & 5 & \multirow[b]{2}{*}{0} \\
\hline & & Inadequado & 0 & \\
\hline & \multirow{2}{*}{ Compactação dos resíduos } & Adequado & 5 & \multirow[b]{2}{*}{0} \\
\hline & & Inadequado & 0 & \\
\hline & Recobrimento dos resíduos & Adequado & 5 & \\
\hline \multirow{2}{*}{$\begin{array}{c}\text { Taludes e } \\
\text { bermas }\end{array}$} & \multirow{2}{*}{ Dimensões e inclinações } & Adequadas & 4 & \multirow{2}{*}{0} \\
\hline & & Inadequadas & 0 & \\
\hline
\end{tabular}


Revista de Geografia (Recife) V. 38, No. 2, 2021

\begin{tabular}{|c|c|c|c|c|}
\hline & \multirow{2}{*}{ Cobertura de terra } & Adequada & 4 & \multirow{2}{*}{0} \\
\hline & & Inadequada & 0 & \\
\hline & \multirow{2}{*}{ Proteção vegetal } & Adequada & 3 & \multirow{2}{*}{0} \\
\hline & & Inadequada & 0 & \\
\hline & \multirow[b]{2}{*}{ Afloramento de chorume } & Não/Raros & 4 & \multirow[b]{2}{*}{0} \\
\hline & & Sim/Numerosos & 0 & \\
\hline \multirow{4}{*}{$\begin{array}{l}\text { Superfície } \\
\text { superior }\end{array}$} & \multirow{2}{*}{ Nivelamento da superfície } & Adequada & 5 & \multirow[b]{2}{*}{0} \\
\hline & & Inadequada & 0 & \\
\hline & \multirow{2}{*}{ Homogeneidade da cobertura } & Sim & 5 & \multirow{2}{*}{0} \\
\hline & & Não & 0 & \\
\hline \multirow{21}{*}{$\begin{array}{c}\text { Estrutura de } \\
\text { proteção } \\
\text { ambiental }\end{array}$} & \multirow{2}{*}{ Impermeabilização do solo } & Sim/adequada & 10 & \multirow{2}{*}{0} \\
\hline & & Não/inadequada & 0 & \\
\hline & \multirow{3}{*}{$\begin{array}{l}\text { Prof. Do lençol freático (p) } x \\
\text { permeabilidade do solo }(k)\end{array}$} & $\mathrm{P}>3 \mathrm{~m} . \mathrm{K}<10-6 \mathrm{~cm} / \mathrm{s}$ & 4 & \multirow{3}{*}{4} \\
\hline & & $\begin{array}{c}1<=\mathrm{p}<=3 \mathrm{~m} . \mathrm{K}< \\
10-6 \mathrm{~cm} / \mathrm{s}\end{array}$ & 2 & \\
\hline & & Inadequada & 0 & \\
\hline & \multirow{2}{*}{ Drenagem de chorume } & Sim/Suficiente & 4 & \multirow{2}{*}{0} \\
\hline & & Não/Insuficiente & 0 & \\
\hline & \multirow{2}{*}{ Tratamento de chorume } & Sim/Adequado & 4 & \multirow[b]{2}{*}{0} \\
\hline & & Não/Inadequado & 0 & \\
\hline & \multirow[b]{2}{*}{ Drenagem provisória de águas pluviais } & Suficiente & 3 & \multirow{2}{*}{0} \\
\hline & & Insuficiente & 0 & \\
\hline & \multirow[b]{2}{*}{ Drenagem definitiva de águas pluviais } & Suficiente & 4 & \multirow{2}{*}{0} \\
\hline & & Insuficiente & 0 & \\
\hline & \multirow{2}{*}{ Drenagem de gases } & Suficiente & 4 & \multirow[b]{2}{*}{0} \\
\hline & & Insuficiente & 0 & \\
\hline & \multirow{3}{*}{ Monitoramento de águas subterrâneas } & Adequado & 4 & \multirow{3}{*}{0} \\
\hline & & Inadequado & 1 & \\
\hline & & Insuficiente & 0 & \\
\hline & \multirow{3}{*}{ Monitoramento geotécnico } & Adequado & 4 & \multirow{3}{*}{0} \\
\hline & & Inadequado & 1 & \\
\hline & & Insuficiente & 0 & \\
\hline \multicolumn{3}{|c|}{ Subtotal 1} & 86 & 4 \\
\hline
\end{tabular}




\begin{tabular}{|c|c|c|c|c|}
\hline \multirow{14}{*}{$\begin{array}{c}\text { Outras } \\
\text { informações }\end{array}$} & \multirow{2}{*}{ Presença de catadores } & Sim & 2 & \multirow{2}{*}{2} \\
\hline & & Não & 0 & \\
\hline & \multirow{2}{*}{ Queima de resíduos } & Não & 0 & \multirow{2}{*}{2} \\
\hline & & Sim & 2 & \\
\hline & \multirow{2}{*}{ Ocorrência de moscas e odores } & Não & 0 & \multirow{2}{*}{2} \\
\hline & & Sim & 2 & \\
\hline & \multirow{2}{*}{ Presença de aves e animais } & Não & 0 & \multirow{2}{*}{2} \\
\hline & & Sim & 2 & \\
\hline & \multirow{2}{*}{ Recebimento de resíduos não autorizados } & Não & 0 & \multirow[b]{2}{*}{2} \\
\hline & & Sim & 2 & \\
\hline & \multirow{2}{*}{ Recebimentos de resíduos industriais } & Sim & & \multirow{2}{*}{-} \\
\hline & & Não & $\mathrm{x}$ & \\
\hline & \multirow{2}{*}{ Estruturas e procedimentos } & Suficiente/Adequado & 10 & \multirow[b]{2}{*}{-} \\
\hline & & Insuficiente/Inadequado & 0 & \\
\hline \multicolumn{3}{|c|}{ Subtotal 2} & 20 & 10 \\
\hline \multirow{9}{*}{$\begin{array}{l}\text { Características } \\
\text { da área }\end{array}$} & \multirow[b]{2}{*}{ Proximidades de núcleos habitacionais } & $>=500 \mathrm{~m}$ & 2 & \multirow{2}{*}{2} \\
\hline & & $<500 \mathrm{~m}$ & 0 & \\
\hline & \multirow{2}{*}{ Proximidades de corpos de água } & $>=200 \mathrm{~m}$ & 2 & \multirow{2}{*}{2} \\
\hline & & $<200 \mathrm{~m}$ & 0 & \\
\hline & \multirow{3}{*}{ Vida útil da área } & $<=2$ anos & & \multirow{3}{*}{-} \\
\hline & & $2<x<5=$ anos & & \\
\hline & & $>5$ anos & $\mathrm{x}$ & \\
\hline & \multirow{2}{*}{ Restrições legais ao uso do solo } & Sim & & \multirow{2}{*}{-} \\
\hline & & Não & $\mathrm{x}$ & \\
\hline \multicolumn{3}{|c|}{ Subtotal 3} & 4 & 4 \\
\hline
\end{tabular}

Entre os agravantes socioambientais observou-se que a área não possui isolamento físico e visual, aterramento dos resíduos, manta de drenagem subterrânea, captação e tratamento de chorume e biogás, consolidando a classificação do dispositivo de disposição final dos RSU como Vazadouro a céu aberto ou aterro comum. Os resíduos coletados são queimados e a fumaça tóxica fica disposta aos transeuntes, provocando poluição atmosférica.

A combustão dos resíduos sólidos urbanos dispostos de forma irregular agrava a poluição atmosférica pela emissão de poluentes, gases de efeito estufa, material particulado Sousa; Bezerra; Lopes, 2021 
tóxico, sendo que estas emissões não estão incluídas nos inventários, porém elas são significativas e merecem expressiva atenção tendo em vista os resultados sobre a saúde humana (WIEDINMYER; YOKELSON; GULLETT, 2014).

Silva, Sá e Borges (2017) avaliaram os problemas advindos da queima dos resíduos sólidos urbanos presente em um vazadouro em Inhumas/GO, relatando: a presença de fumaça, pouca visibilidade na estrada, fuligem, mal cheiro e problemas de saúde.

Tais condições colocam em risco à saúde e ao bem-estar público, uma vez que a disposição inadequada dos resíduos atrai vetores de doenças, animais, além da geração de biogás e chorume, seres humanos expostos a atividades de risco, principalmente os catadores, tendo em vista a condição insalubre. Em estudos realizados por Castro e Oliveira (2020) verificaram que os catadores do lixão de Nepomuceno-MG estavam trabalhando sob condições insalubres, uma vez que estavam expostos a substâncias contaminantes e em contato com animais transmissores de diversas doenças.

A área não possui nenhum mecanismo de proteção ambiental, principalmente no que diz respeito a drenagem dos gases. Estudos realizados por Sousa, Bezerra e Lopes (2020) verificaram que a quantidade de biogás foi de 31.870,23 $\mathrm{m}^{3}$, desse volume produzido, 175,29 $\mathrm{m}^{3}$ e 159,35 $\mathrm{m}^{3}$ correspondem a $\mathrm{NH}_{3}$ e $\mathrm{H}_{2} \mathrm{~S}$, respectivamente. Logo é notória a importância da coleta e tratamento desse subproduto, uma vez que o desprendimento desses gases pode provocar cenários de explosão

Quanto as características da área para implantação de um aterro, algumas restrições devem ser atendidas, segundo a NBR 13.896 (ABNT, 1997) no que se refere a critérios ambientais, operacionais e socioeconômicos, como: distância mínima de $200 \mathrm{~m}$ de qualquer coleção hídrica ou curso d'água; distância mínima de 200 m do sistema viário; distância mínima de $200 \mathrm{~m}$ das falhas geológicas; solos de alta permeabilidade e com aptidão agrícola; unidade geológica com permeabilidade máxima de 30\%; declividade máxima de 8\%; distância mínima de $500 \mathrm{~m}$ da cidade sede - área urbanizada.

No Quadro 2 tem-se o detalhamento dos parâmetros avaliados quanto o Índice de Qualidade de Aterro com Valas (IQR-Valas). 
Quadro 2: Avaliação do Índice de Qualidade de Aterros de Resíduos com Valas do vazadouro a céu aberto de Bom Sucesso, Paraíba.

\begin{tabular}{|c|c|c|c|c|}
\hline ITEM & SUBITEM & AVALIAÇÃO & PESO & PONTOS \\
\hline \multirow{6}{*}{ Estrutura de apoio } & \multirow{2}{*}{ Isolamento físico } & Sim/ Suficiente & 3 & \multirow{2}{*}{0} \\
\hline & & Não/Insuficiente & 0 & \\
\hline & \multirow{2}{*}{ Isolamento visual } & Sim/ Suficiente & 3 & \multirow{2}{*}{0} \\
\hline & & Não/Insuficiente & 0 & \\
\hline & \multirow{2}{*}{ Acesso à frente de cargas } & Adequado & 4 & \multirow[b]{2}{*}{0} \\
\hline & & Inadequado & 0 & \\
\hline \multirow{9}{*}{$\begin{array}{c}\text { Aspectos } \\
\text { operacionais }\end{array}$} & \multirow{2}{*}{ Dimensão das valas } & Adequado & 10 & \multirow{2}{*}{10} \\
\hline & & Inadequado & 0 & \\
\hline & \multirow{3}{*}{ Recobrimento dos resíduos } & Adequado & 10 & \multirow{3}{*}{2} \\
\hline & & Inadequado & 2 & \\
\hline & & Inesxistente & 0 & \\
\hline & \multirow{2}{*}{ Vidal útil } & Suficiente & 5 & \multirow{2}{*}{0} \\
\hline & & Insuficiente & 0 & \\
\hline & \multirow{2}{*}{ Aproveitamento da área } & Adequado & 10 & \multirow{2}{*}{10} \\
\hline & & Inadequado & 0 & \\
\hline \multirow{8}{*}{$\begin{array}{c}\text { Estrutura de } \\
\text { proteção } \\
\text { ambiental }\end{array}$} & \multirow{3}{*}{$\begin{array}{ll}\text { Prof. Do lençol freático }(\mathrm{p}) \\
\\
\text { xpermeabilidade do solo }(\mathrm{k})\end{array}$} & $\mathrm{P}>3 \mathrm{~m} . \mathrm{K}<10-6 \mathrm{~cm} / \mathrm{s}$ & 10 & \multirow{3}{*}{6} \\
\hline & & $\begin{array}{c}1<=\mathrm{p}<=3 \mathrm{~m} . \mathrm{K}< \\
10-6 \mathrm{~cm} / \mathrm{s}\end{array}$ & 6 & \\
\hline & & Inadequada & 0 & \\
\hline & \multirow[b]{2}{*}{ Drenagem de águas pluviais } & Suficiente & 6 & \multirow{2}{*}{0} \\
\hline & & Insuficiente & 0 & \\
\hline & \multirow{3}{*}{ Monitoramento de águas subterrâneas } & Adequado & 6 & \multirow{3}{*}{2} \\
\hline & & Inadequado & 2 & \\
\hline & & Insuficiente & 0 & \\
\hline \multicolumn{3}{|c|}{ Subtotal 1} & 65 & 30 \\
\hline \multirow{5}{*}{$\begin{array}{c}\text { Outras } \\
\text { informações }\end{array}$} & \multirow{2}{*}{ Presença de catadores } & Sim & 0 & \multirow{2}{*}{0} \\
\hline & & Não & 6 & \\
\hline & \multirow{2}{*}{ Queima de resíduos } & Não & 5 & \multirow[t]{2}{*}{0} \\
\hline & & Sim & 0 & \\
\hline & Ocorrência de moscas e odores & Não & 4 & 0 \\
\hline
\end{tabular}




\begin{tabular}{|c|c|c|c|c|}
\hline & & Sim & 0 & \\
\hline & \multirow{2}{*}{ Presença de aves e animais } & Não & 4 & \multirow{2}{*}{0} \\
\hline & & Sim & 0 & \\
\hline & \multirow{2}{*}{$\begin{array}{l}\text { Recebimento de resíduos não } \\
\text { autorizados }\end{array}$} & Não & 6 & \multirow[t]{2}{*}{0} \\
\hline & & Sim & 0 & \\
\hline \multicolumn{3}{|c|}{ Subtotal 2} & 25 & 0 \\
\hline \multirow{9}{*}{$\begin{array}{l}\text { Características } \\
\text { da área }\end{array}$} & \multirow{2}{*}{ Proximidades de núcleos habitacionais } & $>=500 \mathrm{~m}$ & 5 & \multirow{2}{*}{5} \\
\hline & & $<500 \mathrm{~m}$ & 0 & \\
\hline & \multirow{2}{*}{ Proximidades de corpos de água } & $>=200 \mathrm{~m}$ & 5 & \multirow{2}{*}{5} \\
\hline & & $<200 \mathrm{~m}$ & 0 & \\
\hline & \multirow{3}{*}{ Vida útil da área } & $<=2$ anos & & \multirow{3}{*}{-} \\
\hline & & $2<x<5=$ anos & & \\
\hline & & $>5$ anos & $\mathrm{x}$ & \\
\hline & \multirow{2}{*}{ Restrições legais ao uso do solo } & Sim & & \multirow[b]{2}{*}{-} \\
\hline & & Não & $\mathrm{x}$ & \\
\hline \multicolumn{3}{|c|}{ Subtotal 3} & 10 & 10 \\
\hline
\end{tabular}

A partir da avaliação dos critérios do IQR-Valas foi possível constatar que a área não apresenta estrutura de apoio suficiente quanto ao isolamento físico e visual, que baseado na NBR 13.896/1997, a função do isolamento físico é evitar o acesso de pessoas e de animais no local.

Analisando os aspectos operacionais, o aproveitamento da área e dimensão das valas foram considerados adequados. Por outro lado, o recobrimento dos resíduos e a vida útil estão sendo executados de forma inadequada. De acordo com estudos realizados por Lima et al. (2017) ao avaliarem a disposição dos resíduos sólidos urbanos de um aterro no interior do Estado de São Paulo também observaram essas mesmas deficiências em relação aos aspectos operacionais.

No que tange aos fatores de proteção ambiental (drenagem de águas pluviais, monitoramento de águas subterrâneas) todos foram considerados inadequados ou insuficientes. Alves et al. (2020) aplicaram o IQR-Valas para os municípios amazonenses de 
Silves e Itapiranga, e ambos municípios apresentaram indicadores críticos, sendo seus índices inferiores a 1 .

Lunes et al. (2016) realizaram pesquisa semelhante aplicando o método de IQR e IQRvalas na cidade de Pau dos Ferros/RN encontrando resultados similares, com disposição inadequada de resíduos, tríplice poluição, com o agravante de ocorrer afloramento de chorume face a permeabilidade do solo e percolação destes a corpos hídricos próximos. Enquanto no município de Puxinanã/PB, Agreste Paraibano, Pereira e Curi (2017), ao avaliarem o aterro sanitário encontraram condições inadequadas conforme a aplicação do IQR, devido à ausência da cobertura dos resíduos, a não separação de recicláveis e resíduos para compostagem, acumulo de chorume e o não aproveitamento de gases, mostrando que não adianta apenas implementar o aterro, tem que ter gerenciamento com vistas a sustentabilidade.

É possível mudar este cenário, Guerra, Vidal e Souza (2010) encontraram um resultado para o IQR de 4,46 no município de Taquarituba (SP), o que configura condições inadequadas, entretanto com adequações buscando enquadrar a área como: abertura e impermeabilização de trincheiras, recobrimento dos resíduos com o solo retirado nas escavações, drenagem de lixiviado, águas pluviais, gases e o isolamento físico com cercas e guaritas; proporcionaram melhorias ambientais e o aumento do IQR para 9,6 e da vida útil de 4 para 8,8 anos.

Ao avaliar a distribuição espacial em relação aos aspectos socioambientais no entorno do vazadouro foi possível observar sua proximidade em relação a área urbana, bem como a presença de corpos hídricos lênticos a pelo menos de 200 a 500 m do vazadouro (Figura 4). 
Figura 4: Distância do vazadouro de Bom sucesso-PB em relação aos aspectos socioambientais do seu entorno.

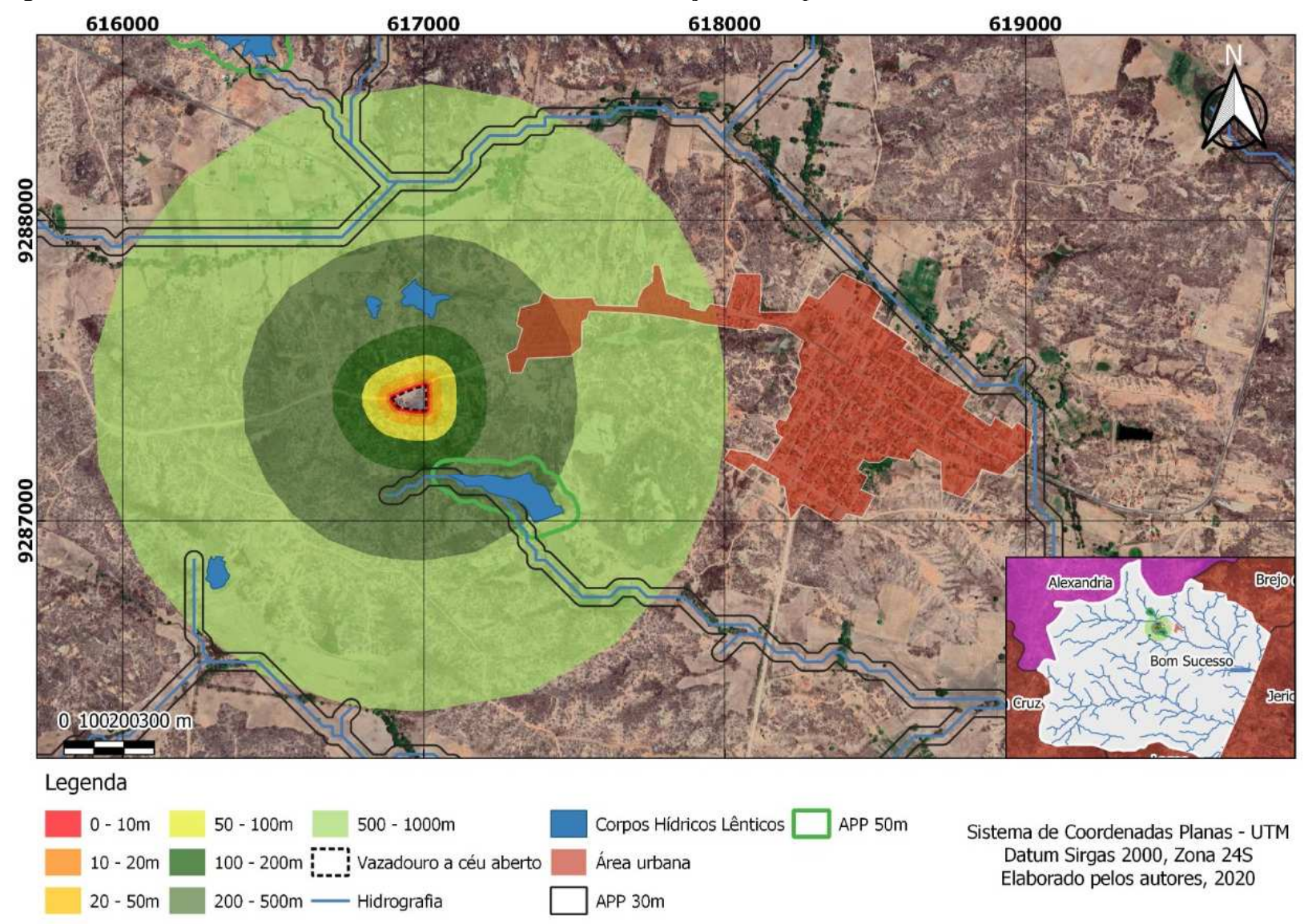

Fonte: Autores, 2020.

A área possui afloramento rochoso o que indica que o lixiviado é carreado quando ocorre precipitação e pode atingir os reservatórios hídricos próximos. Para Posselt e Ries (2015) a disposição dos resíduos sólidos urbanos de forma inadequada resulta em contaminação do solo e da água pela percolação ou infiltração de chorume, que contamina corpos hídricos superficiais e subterrâneas. Outro fator que merece destaque são as APP's dos corpos hídricos de $50 \mathrm{~m}$, os quais apresentam uma importância fundamental, pois possibilitam a conexão de extensões florestais, recarga e regulação hídrica, contenção de erosão e assoreamento e manutenção da diversidade e endemismo de espécies (SANTOS, 2016).

O SNIS (2019) orienta como estratégias, além da mudança para um aterro sanitário, que ocorra a remediação e fechamento do lixão, bem como, a recuperação da área em uso com condições sanitárias e ambientais apropriadas para instalação de um aterro sanitário no local para que continue a receber resíduos. 
Segundo Carvalho et al. (2020) atrelado a estas estratégias, considera-se pertinente a previsão da estimativa de população flutuante, o monitoramento de curto e longo prazo do aterro que se encontra em uso e do que venha a ser implantado. O monitoramento permite que se conheça o grau de contaminação do aterro, bem como, possibilita acompanhar os níveis das emissões de gases e do percolado que é gerado como subproduto da decomposição dos resíduos, fornecendo subsídios aos gestores para diminuir os impactos causados ao meio ambiente.

\section{CONSIDERAÇÕES FINAIS}

A avaliação da destinação final dos resíduos sólidos do município de Bom Sucesso-PB apresentou IQR e IQR-Valas muito baixos, o que decorre da disposição inadequada dos resíduos. A acomodação de resíduos sólidos sem nenhuma preparação pode gerar poluição no meio abiótico (atmosférico, edáfico e aquático) e, consequentemente, danos à saúde da biota.

Não há segregação entre os tipos de resíduos, podendo ser encontrado no vazadouro resíduos provenientes do abate de animais, da construção civil, comercio, agrícola, varrição publica, lixo eletrônico, e lodo provenientes de limpeza de fossas, acarretando periculosidade para os catadores, além de proliferação de vetores.

Além disso, foi possível evidenciar através na análise espacial a proximidade da área urbana em relação ao vazadouro, distante a 1,5 $\mathrm{km}$ ao centro da cidade, e a presença de corpos hídricos, a uma distância de aproximadamente 200 a $500 \mathrm{~m}$.

Com isso, propõem-se adequações conforme a lei 12.305/2010, visando a utilização de um modelo de acomodação de resíduos sólidos que reduza ao máximo os impactos resultantes da disposição inadequada.

\section{REFERÊNCIAS}

ABRELPE, Associação Brasileira de Empresas de Limpeza Pública e resíduos Especiais (São Paulo). Panorama dos resíduos sólidos no Brasil 2019/2020. São Paulo: Abrelpe, 2020, p.52.

ALBERTIN, R. M.; MORAES, E.; ANGELIS NETO, G. de; ANGELIS, B. L. D. de; SCHMIDT, C. A. P. Avaliação da Disposição Final de Resíduos Sólidos Urbanos no Município de Cianorte - Paraná. Tecno - Lógica, v. 15, n.2, p.53-61, jul./dez.2011. 
ALVES, R. C.; SILVA, N. M.; ANDRADE, M. V. B.; MARQUES, E. L. Gerenciamento Municipal de Resíduos Sólidos no Amazonas, Brasil. Research, Society and Development, v. 9 , n. 12, 2020.

BAZIENE, K.; VASAREVICIUS, S. Analysis of a municipal landfill drainage layer using tyre shreds and rubble/Savartyno drenazo sluoksnio uzsikimsimo tyrimas naudojant smulkintas padangas ir skalda. Science - Future of Lithuania, v.4, nº 5, p.430-434, 2012.

BRASIL. Lei n. 12.305, de 02 de agosto de 2010. Institui a Política Nacional de Resíduos Sólidos, altera a lei $\mathrm{n}^{\circ}$ 9.605, de 12 de fevereiro de 1998, e da outras providências. Diário Oficial da União. Brasília, DF, ago. 2010.

BRASIL. Lei $\mathrm{n}^{\circ}$ 12.651, de 25 de maio de 2012. Dispõe sobre a proteção da vegetação nativa; altera as Leis $\mathrm{n}^{\circ} \mathrm{s} 6.938$, de 31 de agosto de 1981, 9.393, de 19 de dezembro de 1996, e 11.428, de 22 de dezembro de 2006; revoga as Leis $n^{\circ}$ s 4.771 , de 15 de setembro de 1965, e 7.754, de 14 de abril de 1989, e a Medida Provisória no 2.166-67, de 24 de agosto de 2001; e dá outras providências. Diário Oficial da União. Brasília, DF, mai. 2012.

CARVALHO, A. L. S. et al. Qualidade de aterro de resíduos na Costa do Descobrimento. Revista de Geografia, Recife, v. 37, n. 2, p. 427-445, 2020.

CASTRO, N. M. A.; OLIVEIRA, B. A. M. Da catação de lixo ao contrato de prestação de serviços de coleta seletiva no município de Nepomuceno: a atuação da RECICLANEP. Revista de Educação Popular, Uberlândia, v. 19, n. 2, p. 290-312, maio-ago. 2020.

CETESB, COMPANHIA AMBIENTAL DO ESTADO DE SÃO PAULO. Inventário Estadual de Resíduos Sólidos Urbanos de 2020. Coordenação e redação Maria Heloisa P. L. Assumpção; equipe técnica Marilda de Souza Soares ... [et al.]; colaborador Fernando Antônio Wolmer - São Paulo: CETESB, 2020, p. 74.

GANDELINI, L.; CAIXETA FILHO, J. V. Otimização dos Aterros Sanitários. Revista de Economia Contemporânea. v.11, n.3 Rio de Janeiro, set./dez. 2007.

GARCÍA-GUAITA, F. Integrating urban metabolism, material flow analysis and life cycle assessment in the environmental evaluation of santiago de Compostela. Sustainable Cities and Society, v. 40, p. 569-580, 2018.

GUERRA, A. F.; VIDAL, C. M. de S.; SOUZA, J. B. de. Proposta de melhoria de aterro de resíduos sólidos urbanos para um pequeno município. Revista Acadêmica, v. 8, n. 2, p.191203, 14 jun. 2017.

HOLGADO-SILVA, H. C.; PADUA, J. B.; CAMILO, L. R.; DORNELES, T. M. A qualidade do saneamento ambiental no assentamento rural Amparo no município de Dourados-MS.

Sociedade \& Natureza, v. 26, n. 3, p.535-545, 2014.

IBGE, INSTITUTO BRASILEIRO DE GEOGRAFIA E ESTATÍSTICA. IBGE Cidades. IBGE, Rio de Janeiro, 2020. Disponível em: https://cidades.ibge.gov.br/brasil/pb/bomsucesso/panorama. Acesso em: 01 out. 2020.

IBGE, INSTITUTO BRASILEIRO DE GEOGRAFIA E ESTATÍSTICA. Malha Municipal. IBGE, Rio de Janeiro, 2017. Disponível em: https://www.ibge.gov.br/geociencias/organizacao-do-territorio/15774-malhas.html?=\&t=oque-e. Acesso em: 01 out. 2020. 
ISMAEL, F. C. M.; LEITE, J. C. A.; SILVA, K. B. Proposta de um Plano de Recuperação para Área do lixão em Pombal-PB. INTESA: Informativo Técnico do Semi-árido. Revista Gvaa, v. 7, n. 1, p.01-19, 2013.

LIMA, P. G.; TAMARINDO, U. G. F; FORTI, J. C.; BRAGA JÚNIOR, S. S. AVALIAÇÃO DE UM ATERRO SANITÁRIO POR MEIO DO ÍNDICE DE QUALIDADE DE RESÍDUOS SÓLIDOS. Brazilian Journal of Biosystems Engineering, v. 11(1): 88-106, 2017.

LOPES, J. R. A. et al. Uso de imagens aéreas para detecção da contaminação do aterro comum de Pau dos Ferros-RN. In: SEMANA DAS ENGENHARIAS QUÍMICA, AMBIENTAL E SANITÁRIA DO OESTE POTIGUAR, 1., 2016, Pau dos Ferros. Anais [...]. Pau dos Ferros: UFERSA, 2016. p. 72-75.

LUNES, A. R. S. et al. Avaliação do lixão do município de Pau Dos Ferros - RN através dos métodos IQR e IQR-Valas. In: SEMANA DAS ENGENHARIAS QUÍMICA, AMBIENTAL E SANITÁRIA DO OESTE POTIGUAR, 1., 2016, Pau dos Ferros. Anais [...]. Pau dos Ferros: UFERSA, 2016. p. 84-87.

MARINO, A. L. et al. Brazilian municipalities have the technical capacity to implement solid waste management at the local level? Journal of Cleaner Production, v. 188, p. 378-386, 2018.

MENDES, J. R. L. et al. Diagnóstico da disposição de resíduos sólidos urbanos no estado da Paraíba. Revista Brasileira de Direito e Gestão Ambiental, v. 8, n. 2, p. 449-457, abr.-jun. 2020.

MINGHUA, Z. et al. Municipal solid waste management in pudong new area, China. Waste Management, v. 29, p. 1227-1233, 2009.

PEREIRA, K. L.; PINTO, L. V. A.; PEREIRA, A. J. Potencial fitorremediador das plantas predominantes na área do lixão de Inconfidentes/MG. Revista Agrogeoambiental, v. 1, n. 1, p.25-29, 31 jul. 2013.

PEREIRA, S. S.; CURI, R. C. Aplicação do índice de qualidade de aterros de resíduos sólidos urbanos no Aterro Sanitário de Puxinanã/PB. Sustentabilidade em Debate, v. 8, n. 1, p.108124, 30 abr. 2017.

POSSELT, H. C.; RIES, L. A. S. Avaliação do processo de biodigestão anaeróbia na geração de biogás a partir de chorume com suplementação de glicerina residual bruta. 2015. Disponível em:

<http://www.lume.ufrgs.br/bitstream/handle/10183/137668/Resumo_43188.pdf?sequence=1> . Acesso em: 13 set. 2020.

POSSELT, H. C.; RIES, L. A. S. Avaliação do processo de biodigestão anaeróbia na geração de biogás a partir de chorume com suplementação de glicerina residual bruta. 2015. Disponível em:

<http://www.lume.ufrgs.br/bitstream/handle/10183/137668/Resumo_43188.pdf?sequence=1> . Acesso em: 13 maio 2021.

SANTOS, A. L. F.; HARAGUCHI, M. T.; LEITÃO, G. C. Índice de qualidade de aterro de resíduos (IQR), como subsídio para avaliar o sistema de disposição final do município de Anápolis-GO. Scientia Plena, v. 8, n. 10, p. 1-20, 2012. 
SANTOS, A. R. et al. Influence of relief on permanent preservation areas. Science of The Total Environment, v. 541, p. 1296-1302, 2016.

SILVA, C. et al. Diagnóstico da contaminação do solo e aplicação do índice de qualidade de aterros de resíduos da CETESB na área de disposição de resíduos sólidos urbanos de PeabirúPR. Engenharia Ambiental, Espírito Santo do Pinhal, v. 9, n. 2, p. 2 52-270, abr/jun. 2012.

SILVA, T. O.; SÁ, F. P.; BORGES, E. C. L. Incêndio no lixão da cidade de Inhumas/GO/Brasil e sua repercussão para a população do município. Revista Meio Ambiente e Sustentabilidade, v. 12, n. 6, p.6-23, 2017.

SOUSA, E. F. de; BEZERRA, J. M.; LOPES, J. R. A. Estimativa da produção de biogás e composição gravimétrica dos resíduos sólidos do município de Bom Sucesso-PB. Novos Cadernos NAEA, v. 23, n. 2, out. 2020.

SOUSA, E. F.; BEZERRA, J. M.; LOPES, J. R. A. Estimativa da produção de biogás e composição gravimétrica dos resíduos sólidos do município de Bom Sucesso-PB. Novos Cadernos NAEA, v. 23, n. 2, p. 201-219, 2020.

SUN, L. et al. Improving waste to energy rate by promoting an integrated municipal solidwaste management system. Resources, Conservation \& Recycling: X, v. 136, p. 289-296, 2018.

TANG, Z. et al. Advanced progress in recycling municipal and construction solid wastes for manufacturing sustainable construction materials. Resources, Conservation \& Recycling: X, v. 6, p. 1-22, 2020.

VREELAND, H.; SCHAUER, J. J.; RUSSELL, A. G.; MARSHALL, J. D.; FUSHIMI, A.; JAIN, G.; SETHURAMAN, K.; VERMA, V.; TRIPATHI, S. N.; BERGIN, M. H. Chemical characterization and toxicity of particulate matter emissions from roadside trash combustion in urban India. Atmospheric Environment, v. 147, p.22-30, 2016.

WALDMAN, M. Resíduos sólidos urbanos domiciliar brasileiro: Modelos de gestão e impactos ambientais. Boletim Goiano de Geografia, v. 33, n. 2, p. 11-26, 2013.

WIEDINMYER, C.; YOKELSON, R. J.; GULLETT, B. K. Global Emissions of Trace Gases, Particulate Matter, and Hazardous Air Pollutants from Open Burning of Domestic Waste.

Environmental Science \& Technology, v. 48, n. 16, p.9523-9530, 2014. 